\title{
Some Suggestions For Teaching Ethics In Business
}

Martin Gritsch, (E-mail: gritschm@wpunj.edu), William Paterson University of New Jersey

\section{INTRODUCTION}

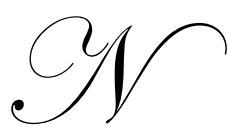
distinguish between illegal practices and legal, yet (at least in the eyes of many a beholder) unethical actions. In a Microeconomic Principles class, which is typically part of an undergraduate Business curriculum, the standard assumption is introduced that a firm aims to maximize its profits. This assumption applies regardless of the market structure (perfect competition, monopolistic competition, oligoply, or monopoly). This gives an instructor the opportunity to point out that-while typically not explicitly mentioned in textbooks-firms are assumed to operate within the confines of the legal system.

However, cases may and do arise in which a possible action does not violate any law, but may be questionable from en ethical standpoint. Below, I will present three examples, which I have successfully used in the classroom. I then briefly suggest other topics in ethics, which lend themselves to classroom discussions. While there is no one right way in which these examples must be presented, I conclude with general suggestions.

\section{SELECTED EXAMPLES FOR CLASSROOM DISCUSSIONS ON “ETHICS IN BUSINESS”}

\section{Trade In Human Organs}

I almost accidentally stumbled across this example in a Microeconomic Principles class a few semesters ago. A little box in the textbook had not much more than a blurb on the trade in human organs. I mentioned it in class, assuming that my students would offer some opinion, and we would leave it at that. I could not have been more wrong! We discussed the subject for the rest of the class period, and came back to it in several of the following classes. This topic had clearly touched a nerve in the students.

Most students have some opinion whether selling human organs should be legal or not. This opinion may be based on religious beliefs, moral grounds, upbringing, or may just be a "gut reaction" (or, of course, a combination of several or all of the above). As I will point out later, we should not try to change a student's opinion. Oftentimes, there is no right or wrong answer to ethical issues. What we can do, however, is to make students think about an issue in objective terms to the extent to which that is possible.

Consider the following example: The kidney is a special organ in the sense that an individual can go through life without substantial problems with only one kidney. The donation of a recently deceased individual's kidney to another individual in need of a kidney transplant seems to be widely accepted in our society. However, given that there are typically no serious medical consequences for a still living donor to donating a kidney, what is wrong with selling it to another individual? The latter person, by paying the agreed-upon amount, reveals his or her preferences in such a way that the benefit of receiving the kidney exceeds the cost associated with the purchase. Similarly, excluding coercion, etc., the seller must value the price that he or she receives more highly than the kidney. In economic terms, this type of transaction increases both the producer surplus and the consumer surplus. 
One thing that can be said for trade in human organs is that selling an organ has the advantage that it will go to the person who values it the most, as expressed by the financial offer. ${ }^{1}$ A case can be made that this will make it superior to mechanisms, which are actually used to match organ donors with recipients. Medical restrictions (matching blood type, geographical proximity, etc.) aside, it used to be the case that the person who had been on the waiting list the longest would receive the transplant. This, as economists who are trained to anticipate "unintended consequences," led to doctors placing patients on the list who were not yet critically ill, as a precautionary measure, so to speak. Thus, if someone suddenly fell gravely ill and would have potentially benefited tremendously from a transplant, he or she had to get "in line" which often meant that the person would pass away before an organ became available. More recently, the typically employed system attempts to award a transplant organ to the person who is anticipated to reap the highest benefit from the transplant, i.e., severity of illness and projected success of the transplant operation are taken into consideration. While I am not aware of any cases of foul play (and I do not suggest that it exists!), it is clear that the incentive for exaggerating a diagnosis does exist, i.e., the system lacks the objectivity of awarding an organ to the person who was placed on the list the longest time ago.

Another useful angle may be to ask students what the difference is between selling blood to a blood bank (or semen to a sperm bank or an egg to a willing buyer) and selling a non-vital organ. While differences do exist between these examples, are they substantial enough in nature that these things should receive different legal treatment?

Discussions about this topic do not only provide students with insights into a very relevant and timely public policy issue, but they will also show students that some things may not be as clear-cut as they appear at first. It forces them to think about some of their (often firmly-held) beliefs.

\section{Who Gets What Kind Of Medical Care?}

The costs of medical care have risen substantially in recent years. In particular, the last few months in a person's life contribute substantially to the total amount spent on an individual during his or her lifetime. It would save an economy's health care system a large amount of money if treatment, which extends life by merely a few months (if that!) would not be provided. Can policymakers (or insurance companies) deny seriously ill patients certain expensive procedures when the expected added life expectancy can be measured in weeks or months rather than years? Most students find the idea that such kinds of treatment should be denied appalling. However, dependent on the type of health insurance an individual carries, certain procedures are not covered either. In addition, many health insurance policies do not leave the subscriber freely choose the point of service. This is less of an issue for routine checkups, etc., but it can become a big one for sophisticated (and expensive) procedures. Moreover, many health plans have annual or lifetime maximum amounts, which are easily high enough for a large majority of subscribers. However, for the few individuals who do reach that maximum, it effectively means the denial of medical care. Yet, many students are much less upset by that idea than by the suggestion that someone should have the right to deny medical treatment to someone whose chances of having his or her life prolonged considerably are very small.

\section{Exploitation Of Labor?}

How do we feel about workers who do hard work for little pay? More specifically, consider the following two scenarios: First imagine workers, often illegal immigrants, laboring in poor conditions for low pay in a sweatshop in the United States. Then consider the working conditions and pay scales in many developing countries where much of, e.g., the products of the U.S. textile and apparel industries are produced. In my view, this is just another example of the well-known analogy between foreign workers working abroad so that the final products are imported to the United States and the "import" of the input factor labor via immigration. Aside from such issues that immigration is much more likely to be permanent than import of goods, these two scenarios are qualitatively equal to each other. From an ethical perspective, are we more upset about the first situation (poor working conditions and low pay in the U.S.) than the second one (poor working conditions and low pay abroad)? I believe that to be the case for many individuals, which begs for the question why that is the case.

\footnotetext{
${ }^{1}$ This assumes perfect flow of information among potential sellers and potential buyers. Here's an interesting extension: Should it be allowed to post sales offers for human organs on an Internet auction site such as eBay? This would address the issue of information flow while not altering the underlying transaction between buyer and seller.
} 
To add some complexity to this issue, suggest the following to students: It is a sad fact that in many developing countries, young children are forced by economic conditions to work to support their families. Even if working conditions and pay are not great by American standards, is it not better than some of the common "alternatives" (prostitution, mugging tourists, etc)?

For example, in the textile and apparel industry, many U.S. firms used to have large production facilities in the U.S. for many years. In the meantime, this has become the exception rather than the rule. I believe that it is fair to say that it has become very difficult for such firms to be profitable if they refuse to move their production to counties with substantially lower wage rates. This problem may best be appreciated by asking the students to pretend that they run such a company in the United States. After a careful review of the requisite numbers, it appears clear that the company cannot survive in the long run if production is kept domestically. Is it unethical to shift production to countries with poor working conditions? If students feel that that is the case, ask them how they feel about associated white-collar workers in the U.S. whose jobs may be saved by moving production abroad. I am not suggesting that there is a clear-cut answer to these questions. Oftentimes, there are no easy answers to these problems. In my opinion, many ethical issues can be used in the classroom to stimulate discussion and critical thinking.

\section{OTHER SUGGESTED TOPICS FOR DISCUSSION}

Before I conclude with general recommendations, I list a number of other topics that deal with the issue of ethics in business decisions. In most cases, they are phrased in the form of a relatively provocative question. Please note that I am not taking a position on these topics. The questions are meant to evoke a response on the students' part. Oftentimes, after asking the initial provocative question, I ask a question which deals with a topic which is quite similar in a number of ways, but often receives different treatment )in terms of public opinion or legality). Students should think these problems through and analyze them in terms of their similarities and differences.

\section{How Much Is A Life Worth?}

Students often object to the notion of attaching a dollar figure to a person's life (e.g., when damages are assessed in a wrongful death lawsuit). However, they typically agree with the concept of different amounts of life insurance coverage for different individuals (e.g., 35-year old sole income earner of a family with four young children vs. retiree with no dependents). After this comparison, it often makes more sense to students that a similar thought process be employed in the determination of damages should a person get killed due to somebody else's negligence. It should be stressed that this does not mean that one person is not considered to be more "valuable"; it is a question of earning potential.

\section{Should Pharmaceutical Companies Be Required To Deliver Medication To Developing Countries At Or Below Cost?}

If so, should we force a physician to donate some of his/her time to work as a volunteer in a developing country? Or, should we force a carmaker to donate cars?

\section{Should Prostitution Be Legal?}

It seems that the willingness to pay on the buyer's part exceeds the price. If we are concerned about the moral issues associated with the provision of such services, why is the production of adult movies legal?

\section{Should The U.S. Export Military Products?}

If so, to which countries? Many people are critical of the sale of arms to a variety of foreign countries. At the same time, it is probably fair to say that other countries would be willing to supply these countries with weapon technology if the U.S. refused to do so. Is this enough of a moral justification to do it? 


\section{SUMMARY AND GENERAL RECOMMENDATIONS}

Generally, when discussing ethical issues in a business course, I suggest the following approach:

- $\quad$ State the issue in the form of a provocative question or statement. This will pique the students' curiosity.

- $\quad$ Let them express their "gut reaction."

- If feasible, let the students discuss the topic among themselves with your guidance.

- While I feel that it is very important not to force an opinion on students, if there is an objective "solution" provided by, e.g., economic theory (in addition to laws), do mention it.

- $\quad$ Then stress that economic considerations should not be the only ones.

"Ethics in Business" is clearly a very timely issue. I feel that it is important that ethical issues are incorporated in the teaching of today's students. While some universities and colleges devote an entire course to the teaching of ethics in business (which is certainly not a bad idea), it should be supplemented by discussions of ethics issues in as many classes as possible. The examples above have worked well for me in my classes. Numerous other examples exist, which should be used to add an ethical component to the decision-making skills of tomorrow's business leaders 